\title{
EGFR/HER2 Kinase Inhibitor TAK-285
}

National Cancer Institute

\section{Source}

National Cancer Institute. EGFR/HER2 Kinase Inhibitor TAK-285. NCI Thesaurus. Code C90589.

An orally bioavailable, small molecule and dual kinase inhibitor of human epidermal growth factor receptors 1 (EGFR/ErbB1) and 2 (HER2/ErbB2), with potential antineoplastic activity. EGFR/HER2 kinase inhibitor TAK-285 binds to and inhibits EGFR and HER2, which may result in the inhibition of tumor growth and angiogenesis, and tumor regression in EGFR/HER2-expressing tumors. This agent may be active against EGFR/HER2-expressing tumor cells that are resistant to trastuzumab. EGFR and HER2, receptor tyrosine kinases overexpressed in a variety of tumor cell types, play major roles in tumor cell proliferation and tumor vascularization. In addition, TAK-285 appears to pass the blood brain barrier (BBB) and does not appear to be a substrate for efflux pumps. 